\title{
STUDI KONSENTRASI CO AKIBAT KENDARAAN BERMOTOR DI KAWASAN PASAR TRADISIONAL KOTA PADANG
}

\author{
STUDY OF CO CONSENTRATIONS DUE TO MOTOR \\ VEHICLES IN THE TRADITIONAL MARKET OF PADANG \\ CITY
}

\author{
Vera Surtia Bachtiar, Vivin Alfirna \\ Jurusan Teknik Lingkungan Universitas Andalas \\ Kampus Universitas Andalas Limau Manis Padang \\ Email: vera_sb@ft.unand.ac.id; vera.surtia@gmail.com
}

\begin{abstract}
ABSTRAK
Kawasan pasar tradisional Kota Padang merupakan kawasan dengan aktivitas transportasi kendaraan bermotor yang cukup tinggi. Penelitian ini bertujuan untuk mengetahui kualitas udara untuk parameter CO akibat kendaraan bermotor di Kota Padang. Pengukuran konsentrasi CO dilakukan di pasar tradisional di Kota Padang yang berada dekat jalan raya, yaitu Pasar Bandar Buat, Pasar Raya Padang dan Pasar Lubuk Buaya untuk melihat pengaruhnya dari aktivitas transportasi kendaraan bermotor. Pengukuran CO dilakukan menggunakan CO meter selama satu jam pada jam sibuk (07.00-08.00 wib, kecuali untuk Pasar raya Padang, dilakukan pukul 16.00-17.00 wib) dan jam senggang (10.00-11.00 wib). Konsentrasi CO saat jam sibuk berkisar 5,92-11,67 ppm, sedangkan pada jam senggang sebesar 4,58 - 9,25 ppm. Bagian luar pasar tradisional (8,50-11,67 ppm) memiliki konsentrasi CO lebih tinggi dari pada bagian dalamnya (4,58-5,92 ppm). Konsentrasi CO terukur di setiap lokasi masih berada di bawah baku mutu. Artinya, adanya arus lalu lintas di kawasan pasar tradisional di Kota Padang mempengaruhi kualitas udara pada pinggir jalan raya, tetapi tidak begitu mempengaruhi kualitas udara di kawasan dalam pasar tradisonal tersebut.
\end{abstract}

Kata kunci: Transportasi, Kendaraan Bermotor, Konsentrasi CO, Pasar tradisional.

\begin{abstract}
The traditional market area in Padang City is an area with a fairly high transportation activity of motor vehicles. The aims of this study is to determine the air quality for $C O$ parameter due to motor vehicles in Padang City. The measurement of $\mathrm{CO}$ concentration was conducted in the traditional markets in Padang City which were located near the highway, namely Bandar Bandar Market, Pasar Raya Padang Market and Lubuk Buaya Market to see the effect of motor vehicle on transportation activity. CO measurements were carried out using $C O$ meters for one hour during peak hours (07.0008.00, except for Pasar Raya Market, conducted at 16.00-17.00) and off-peak hours (10.00-11.00 wib). CO concentrations during peak hours range between 5.92 and 11.67 ppm, while in the off-peak hours between 4.58 and 9.25 ppm. The outside of the traditional market (8.50-11.67 ppm) which is located on the edge of the highway, has a higher CO concentration than the inside (4.58-5.92 ppm). The measured CO concentrations in each location are below the national air quality standards. It means, the presence of traffic flow in the traditional market area in Padang City affects air quality on the edge of the highway, but not so affect the air quality in the inside area in the traditional market.
\end{abstract}

Keywords: Transportation, Motor Vehicle, CO Concentration, Traditional Market. 


\section{PENDAHULUAN}

Pertumbuhan ekonomi dan pembangunan di segala bidang telah berkembang dengan pesat. Pembangunan fisik kota dan berdirinya pusat-pusat industri disertai dengan melonjaknya produksi kendaraan bermotor mengakibatkan peningkatan kepadatan lalu lintas dan hasil produksi sampingannya. Perkembangan tersebut telah menimbulkan dampak terhadap kualitas lingkungan hidup khususnya di perkotaan yang semakin lama cenderung semakin menurun. Salah satu dampak negatif yang ditimbulkannya adalah penurunan kualitas udara.

Berdasarkan estimasi WHO tahun 2004, jumlah $\mathrm{CO}$ dari sumber buatan diperkirakan mendekati 60 juta ton per tahun. $90 \%$ dari konsentrasi CO di udara perkotaan berasal dari kendaraan bermotor. Kadar $\mathrm{CO}$ di perkotaan cukup bervariasi tergantung dari kepadatan kendaraan bermotor dan umumnya ditemukan kadar $\mathrm{CO}$ yang bersamaan dengan jam-jam sibuk (Abubakar, 2001). Selain itu, variasi kadar $\mathrm{CO}$ juga dipengaruhi oleh cuaca. Gas CO sebagai gas yang tidak berwarna, tidak berbau dan tidak berasa, sehingga sulit untuk merasakan langsung keberadaannya oleh indera manusia. Paparan CO ini akan menimbulkan gangguan seperti sakit kepala, gangguan pernapasan, muntah-muntah, serangan jantung, koma bahkan kematian.

Padang merupakan ibukota Provinsi Sumatera Barat yang perkembangannya terus berlanjut di berbagai bidang. Salah satu sarana yang cukup besar peranannya dan terus berkembang di Kota Padang adalah sarana transportasi. Berdasarkan data Badan Pusat Statistik Kota Padang tahun 2011, Kota Padang mempunyai jumlah kendaraan bermotor cukup tinggi, yaitu 421.265 unit. Semakin banyak jumlah kendaraan bermotor akan menyebabkan produksi $\mathrm{CO}$ semakin tinggi karena hasil pembakaran bahan bakar kendaraan tersebut. Hal ini menunjukkan semakin tingginya kemungkinan masyarakat Kota Padang terpapar gas $\mathrm{CO}$ yang membahayakan kesehatan.
Pasar tradisional di Kota Padang merupakan kawasan fasilitas umum dengan banyak masyarakat yang beraktivitas, serta memiliki banyak aktivitas transportasi dan cenderung menjadi salah satu titik kemacetan lalu lintas di Kota Padang. Padatnya kendaraan bermotor di pasar tradisional akan memproduksi konsentrasi $\mathrm{CO}$ yang lebih tinggi. Hal ini berdampak buruk terhadap masyarakat yang beraktivitas di kawasan tersebut, seperti pedagang.

CO meter merupakan sebuah teknologi alat ukur pendeteksi $\mathrm{CO}$ yang mampu mendeteksi $\mathrm{CO}$ dengan cepat dan menginterpretasikan tingkat racun $\mathrm{CO}$ di udara. Pengukuran $\mathrm{CO}$ menggunakan $\mathrm{CO}$ meter dapat dilakukan di berbagai lokasi dan kondisi karena $\mathrm{CO}$ yang dideteksi memiliki massa jenis yang sama dengan udara. Untuk kawasan pasar tradisional yang menerima emisi CO dari kendaraan bermotor dengan cepat perlu pengidentifikasian konsentrasi $\mathrm{CO}$ yang terpapar ke reseptor dengan cepat dan praktis. Adanya penelitian untuk mengetahui konsentrasi $\mathrm{CO}$ yang akan terhirup oleh reseptor dengan teknologi ini diharapkan dapat dijadikan pertimbangan dalam menentukan tindakan terkait polusi udara yang terjadi khususnya di kawasan Pasar tradisional Kota Padang.

\section{METODOLOGI}

Pengumpulan data yang dilakukan adalah pengumpulan data primer dan sekunder, yaitu data primer berupa data pengukuran konsentrasi $\mathrm{CO}$, data meteorologi, data jumlah kendaraan di lokasi studi, sedangkan data sekunder berupa data kepadatan lalu lintas, serta data jumlah pasar tradisional di Kota Padang untuk menentukan jumlah dan lokasi pengukuran.

Penentuan jumlah dan lokasi pengukuran dilakukan dengan metode purposive random sampling, sehingga didapatkan tiga pasar tradisional dari 11 pasar tradisional yang dikelola pemerintah Kota Padang. Dasar pertimbangan terpilihnya lokasi tersebut, antara lain: lokasi yang berada di pinggir jalan raya, kepadatan ruas jalan raya, tingkat kemacetan yang terjadi, persebaran titik sampling di Kota Padang. 
Pengukuran Konsentrasi Gas CO di lokasi studi yang diukur menggunakan $\mathrm{CO}$ meter/detektor, selama satu jam dengan pengukuran setiap lima menit. Di setiap lokasi pengambilan sampel dilakukan pengukuran $\mathrm{CO}$ sebanyak 2 titik yang berbeda, untuk melihat pengaruhnya terhadap konsentrasi CO.

Dalam PP no 41 Tahun 1999 tentang pengendalian Pencemaran Udara, pengukuran $\mathrm{CO}$ dilakukan dengan metode analisis NDIR menggunakan peralatan NDIR Analyzer. Akan tetapi karena keterbatasan alat, maka digunakan $\mathrm{CO}$ meter. Setelah dilakukan pengujian, $\mathrm{CO}$ meter ini mempunyai akurasi yang sama dengan impinger, alat sampling untuk gas yang ada di Laboratorium Kualitas Udara Jurusan Teknik Linngkungan.

CO meter ini dapat digunakan untuk mengukur konsentrasi $\mathrm{CO}$ di udara ambien dalam interval 0-1000 ppm. Jika konsentrasi $\mathrm{CO}$ di udara melebihi $200 \mathrm{ppm}$, secara otomatis alarm akan berbunyi secara kontinu. Jika konsentrasi CO yang terukur berada dalam rentang $35 \mathrm{ppm}-200 \mathrm{ppm}$ akan berbunyi pendek dan putus-putus. Tipikal alat ini adalah: dapat dioperasikan pada suhu $0-50{ }^{\circ} \mathrm{C}$, temperatur penyimpanan $-30-60{ }^{\circ} \mathrm{C}$, tipe sensor adalah stabilized electrochemical gas specific $\mathrm{CO}$ dan akurasi alat $\leq 5 \%$. Untuk lebih jelasnya, alat CO meter dapat dilihat pada gambar 1.

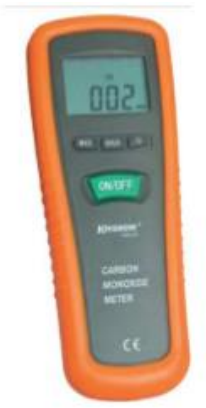

Gambar 1. CO Meter

Pengukuran Jumlah lalu lintas diperoleh dari pengukuran langsung di lapangan, yaitu pada titik pengambilan sampel gas $\mathrm{CO}$ (titik 1). Data yang didapatkan berupa jumlah kendaraan per lima menit selama melakukan pengukuran konsentrasi $\mathrm{CO}$.
Data meteorologi Data meteorolgi diukur menggunakan alat pocket weatherman untuk pengukuran suhu, kelembaban dan tekanan udara. Untuk pengukuran kecepatan angin digunakan anemometer dan kompas untuk menentukan arah angin

Untuk pengambilan data primer di kawasan pasar tradisional kota Padang dilakukan di dua titik di setiap lokasi pengukuran, yakni di bagian dalam dan luar pasar tradisional. Pengukuran dilakukan pada jam sibuk 7.00 8.00 wib dan pada jam senggang yakni pukul 10.00-11.00 wib. Khusus untuk Pasar Raya pengukuran untuk jam sibuk dilakukan pada pukul 16.00 - 17.00 wib. Pengukuran CO di pasar tradisional dilakukan di Pasar Bandar Buat, Pasar Lubuk Buaya dan Pasar Raya Padang bagian Barat. Untuk jelasnya, lokasi titik sampling dapat dilihat pada gambar 2, gambar 3 dan gambar 4.

Pengukuran $\mathrm{CO}$ ini dilakukan pada saat aktivitas kendaraan yang padat dan saat kendaraan sepi, dengan jangka waktu masing-masingnya selama satu jam. Hal ini dilakukan untuk melihat variasi konsentrasi $\mathrm{CO}$ di lokasi pengukuran dan melihat tingkat CO maksimum yang terjadi selama pengukuran serta mendapatkan gambaran konsentrasi rata-rata yang diterima oleh reseptor yaitu pedagang lesehan atau pedagang kaki lima.

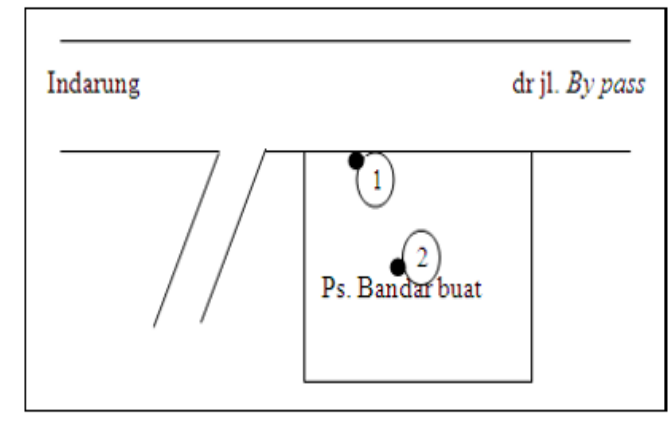

Gambar 2. Titik sampling Pasar Bandar Buat

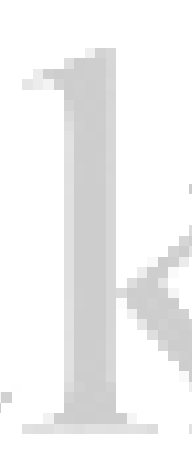




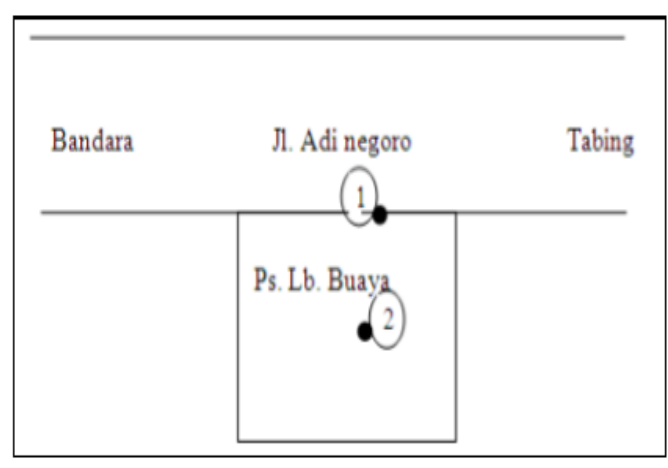

Gambar 3. Titik sampling Pasar Lubuk Buaya

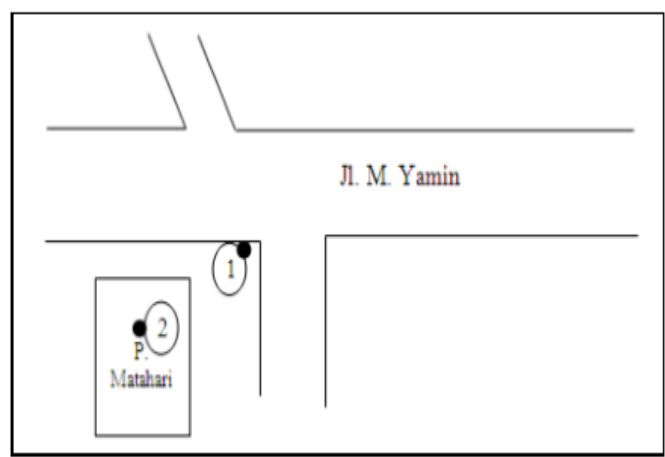

Gambar 4. Titik sampling Pasar Raya Padang

Dalam penelitian ini, sumber $\mathrm{CO}$ yang diperkirakan di jalan raya adalah dari kendaraan bermotor dengan dipengaruhi oleh arah dan kecepatan angin. Analisis dilakukan terhadap variabel tersebut dalam konsentrasi. Variasi konsentrasi $\mathrm{CO}$ dari setiap titik pengukuran dianalisis berdasarkan jumlah kendaraan, kondisi meteorologi serta posisi dan kondisi titik pengambilan sampel tersebut.

Untuk menganalisis konsentrasi $\mathrm{CO}$ yang terukur dengan membandingkan terhadap standar baku mutu yang ada, yakni: PP No. $41 / 1999$, tentang pengendalian pencemaran udara.
Penentuan korelasi antara konsentrasi CO di setiap kawasan dengan jumlah kendaraan pada saat sampling, ditentukan dengan persamaan regresi. Nilai korelasi $r$ dapat ditentukan dengan persamaan koefisien korelasi Pearson (Zulaela, 2010).

$\mathrm{r}=\frac{n \sum_{i=1}^{n} x i y i-\left(\sum_{i=1}^{n} x i\right)\left(\sum_{i=1}^{n} y i\right)}{\sqrt{\left[\sum_{i=1}^{n} x i^{2}-\left(\sum_{i=1}^{n} x i\right)^{2}\right]\left[\sum_{i=1}^{n} y i^{2}-\left(\sum_{i=1}^{n} y i\right)^{2}\right]}}$

dimana:

$\mathrm{r} \quad=$ koefisien korelasi

$\mathrm{n} \quad=$ jumlah sampel

$\mathrm{x}=$ nilai variabel bebas

$\mathrm{y} \quad=$ nilai variabel terikat

Hasil nilai $r$ yang diperoleh dari perhitungan diinterpretasi ke dalam suatu penilaian untuk melihat jenis hubungan kedua parameter.

\section{HASIL DAN PEMBAHASAN}

\section{Data Meteorologi Lokasi Studi}

Pengukuran meteorologi di lokasi studi dilakukan sejalan dengan pengukuran konsentrasi $\mathrm{CO}$, disesuaikan dengan jam padat dan jam senggang kendaraan selama aktivitas pada masing-masing lokasi.

Berdasarkan Tabel 1 terlihat bahwa hasil pengukuran meteorologi untuk suhu dan kelembaban di setiap lokasi relatif sama. Adanya perbedaan tekanan udara yang terjadi di setiap lokasi pengukuran dipengaruhi oleh perbedaan ketinggian kawasan tersebut. Tekanan udara akan mengalami penurunan $1 \mathrm{mmHg}$ setiap kenaikan tinggi suatu wilayah sebesar 11 meter (Putut, 2011). 
Tabel 1. Data Meteorologi

\begin{tabular}{|c|c|c|c|c|c|c|c|}
\hline \multirow[b]{2}{*}{ No. } & \multirow{2}{*}{$\begin{array}{c}\text { Lokasi } \\
\text { Sampling }\end{array}$} & \multirow[b]{2}{*}{ Waktu } & \multicolumn{5}{|c|}{ Data Meteorologi } \\
\hline & & & $\mathbf{T}\left({ }^{\circ} \mathbf{C}\right)$ & RH (\%) & P (inHg) & $\begin{array}{c}\mathbf{V x} \\
(\mathbf{m} / \mathbf{d e t})\end{array}$ & $\begin{array}{c}\text { Arah Angin } \\
\text { Dominan }\end{array}$ \\
\hline \multirow{2}{*}{1} & \multirow{2}{*}{$\begin{array}{l}\text { Pasar } \\
\text { Bandar } \\
\text { Buat } \\
\end{array}$} & $07.00-08.00$ & 27,49 & 81,39 & 29,43 & 0,37 & BL \\
\hline & & $10.00-11.00$ & 31,72 & 72,77 & 29,43 & 0,24 & BL \\
\hline \multirow{2}{*}{2} & \multirow{2}{*}{$\begin{array}{l}\text { Pasar } \\
\text { Lubuk } \\
\text { Buaya }\end{array}$} & $07.00-08.00$ & 28,08 & 78,36 & 29,89 & 0,4 & $\mathrm{BD}$ \\
\hline & & $10.00-11.00$ & 31,98 & 70,03 & 29,89 & 0,53 & $\mathrm{BL}$ \\
\hline \multirow{2}{*}{3} & \multirow{2}{*}{$\begin{array}{l}\text { Pasar Raya } \\
\text { Barat }\end{array}$} & $16.00-17.00$ & 30,3 & 79,63 & 29,82 & 0,21 & BL \\
\hline & & $10.00-11.00$ & 29,19 & 84,66 & 29,82 & 0,24 & $\mathrm{BL}$ \\
\hline
\end{tabular}

Ket: $\mathrm{T}$ : Suhu RH : Kelembaban

$\mathrm{P}$ : Tekanan Vx : Kec. Angin

BD: Barat Daya BL:Barat Laut

Perbedaan tekanan udara di setiap tempat menyebabkan terjadinya gerakan udara atau angin. Udara akan bergerak dari daerah bertekanan tinggi menuju daerah yang bertekanan rendah. Kecepatan angin yang didapatkan selama pengukuran yakni $0-1$ $\mathrm{m} /$ detik. Kecepatan angin mempengaruhi besar kecilnya konsentrasi polutan dimana semakin tinggi kecepatan angin, maka konsentrasi akan semakin kecil, Istantinova, $\mathrm{dkk}$, 2012. Lemah kuatnya gerakan udara

mempengaruhi konsentrasi polutan suatu wilayah. (Supriyadi, 2009).

\section{Jumlah Kendaraan Lalu Lintas di Kawasan Pasar Tradisional Kota Padang}

Hasil pengukuran jumlah kendaraan di ketiga lokasi pengukuran pasar tradisional di Kota Padang didapatkan dalam grafik Gambar 5. Pengukuran dilakukan saat jam sibuk (07.00-08.00 wib, kecuali Pasar Raya Padang Bagian Barat 16.00-17.00 wib) dan saat jam senggang (10.00-11.00 wib).

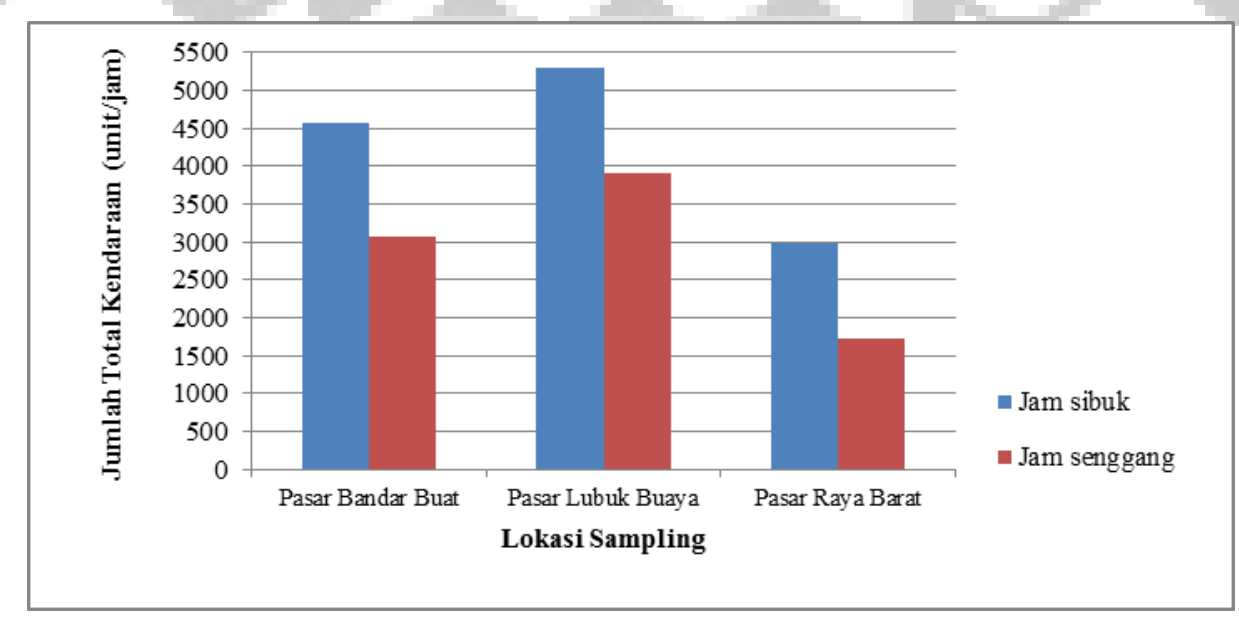

Gambar 5. Jumlah Kendaraan di Lokasi Sampling Pasar Tradisional

Dari tiga lokasi sampling pasar tradisional tersebut, jumlah kendaraan tertinggi terjadi di kawasan Pasar Lubuk Buaya baik saat jam sibuk ataupun jam senggang kendaraan. Jalan yang melintas di depan Pasar Lubuk Buaya ini merupakan jalan raya Padang -
Bukittinggi, selain itu di sekitar kawasan ini terdapat kawasan komplek sekolah yang cukup mempengaruhi jumlah kendaraan di kawasan tersebut khususnya pada pagi hari saat aktivitas sekolah akan dimulai. Pasar Raya Padang Bagian Barat memiliki jumlah kendaraan terkecil karena kemacetan akibat 
angkutan umum yang sering berhenti sembarangan di lokasi ini serta adanya larangan untuk kendaraan berat.

\section{Konsentrasi CO di Kawasan Pasar Tradisional Kota Padang}

Berdasarkan gambar 6, hasil pengukuran konsentrasi $\mathrm{CO}$ yang didapatkan dari ketiga lokasi pasar tradisional cenderung hampir sama, meskipun terdapat perbedaan yang cukup signifikan pada jumlah kendaraan di ketiga lokasi tersebut. Pasar Raya Barat dengan jumlah kendaraan terendah memiliki konsentrasi CO yang lebih tinggi. Di Pasar Raya Barat ini sering terjadi kemacetan lalu lintas karena banyaknya kendaraan (angkutan umum) yang berhenti atau dalam kondisi idle untuk mencari penumpang.

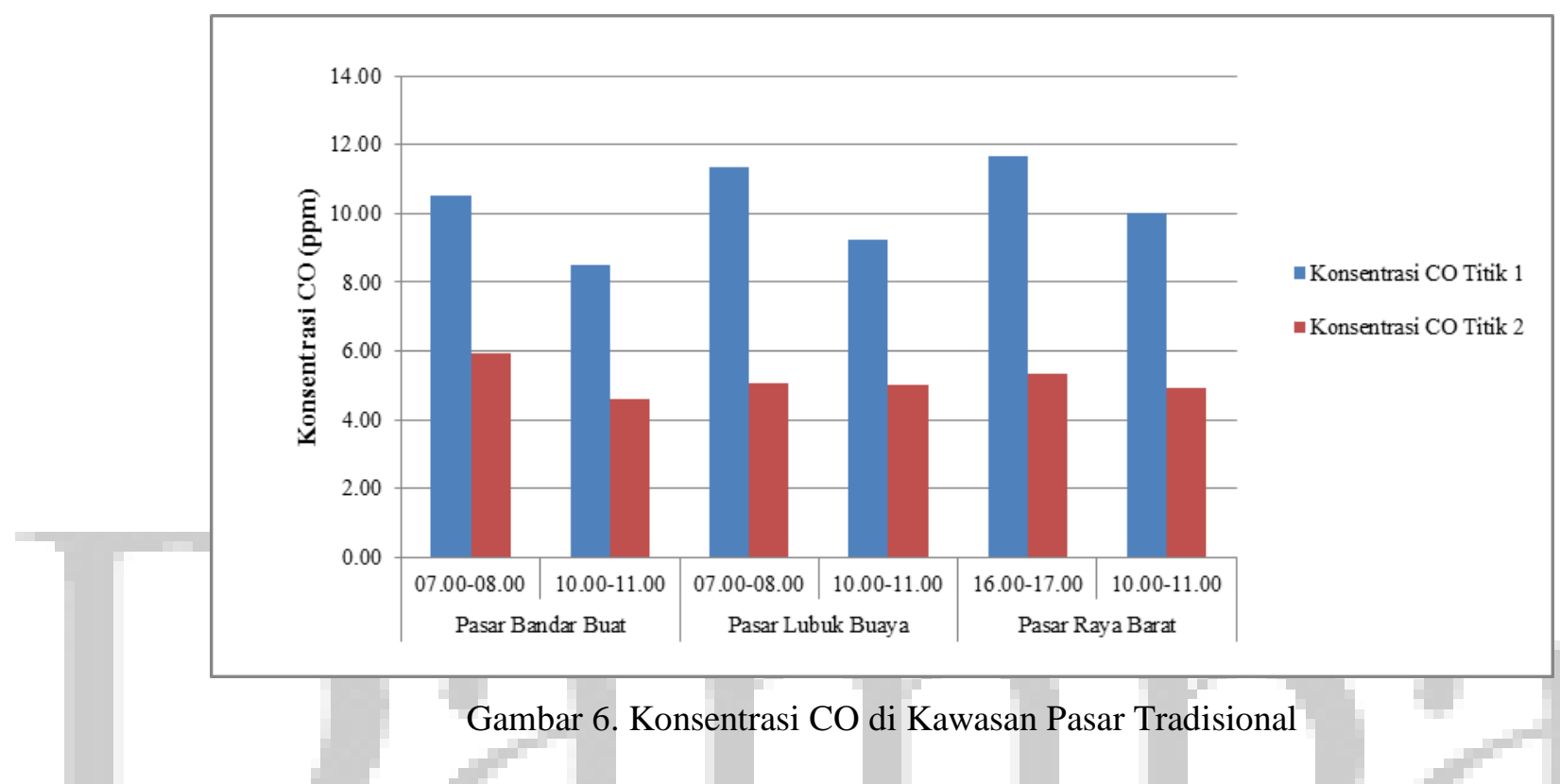

Jumlah ini mempengaruhi tingginya konsentrasi CO terukur. Selain itu, pada jarak 4- 5 meter dari Titik 1 pengukuran di Pasar Raya adanya aktivitas pedagang yang menggunakan kompor gas untuk memasak dengan 2 buah kompor yang sedang beroperasi. Kompor yang beroperasi juga mengeluarkan emisi gas $\mathrm{CO}$.

Konsentrasi CO terendah terjadi di Pasar Bandar Buat. Kawasan pasar tradisional ini merupakan perlintasan kendaraan pabrik berupa kendaraan berat menuju pabrik semen sehingga lebih banyak dilewati oleh kendaraan berbahan bakar solar dimana emisi CO yang dikeluarkan kendaraan berbahan bakar solar lebih kecil daripada kendaraan dengan bahan bakar bensin. Menurut laporan Badan Proteksi Lingkungan Amerika tahun 1990 dalam Suryani (2010), bahan bakar bensin mengeluarkan gas buang $\mathrm{CO}$ paling besar jika dibandingkan solar (Bachtiar 2005). Tingkat konsentrasi $\mathrm{CO}$ di atmosfer berkolerasi positif terhadap padatnya lalu lintas (Suryani, 2010).

Konsentrasi $\mathrm{CO}$ bagian dalam pasar tradisional mengalami penurunan dibandingkan saat di bagian luar pasar. Hal ini disebabkan jarak sumber $\mathrm{CO}$ lebih jauh dibandingkan dengan bagian luar. Semakin jauh jarak antara sumber peolutan dengan reseptor, maka konsentrasi $\mathrm{CO}$ yang dihasilkan akan semakin kecil (Bachtiar, dkk, 2016). Untuk titik pengukuran di bagian dalam pasar tradisional, menunjukkan hasil konsentrasi $\mathrm{CO}$ yang hampir sama baik saat jam sibuk maupun jam. Berdasarkan hal tersebut, dapat dikatakan bahwa untuk konsentrasi CO di bagian dalam pasar tradisional tidak terlalu dipengaruhi oleh jumlah kendaraan yang melewati kawasan pasar tradisional tersebut. Lokasi titik 2 di setiap pasar tradisional berada di kawasan tertutup oleh bangunan permanen ataupun bangunan semi permanen yang dibuat pedagang. Konsentrasi CO yang 
terukur di bagian dalam pasar tradisional ini juga dapat bersumber dari asap rokok dari para perokok yang berkeliaran di pasar tradisional.

Saat pengukuran $\mathrm{CO}$, dilakukan pengukuran terhadap kondisi meteorologi seperti suhu, kelembaban relatif, arah dan kecepatan angin. Kecepatan angin yang terukur di setiap lokasi pasar tradisional berada pada rentang $0-1 \mathrm{~m} /$ detik, yang tergolong angin tenang. Menurut supriyadi (2009), hal ini perlu diwaspadai karena kemampuan angin untuk untuk mencampurkan polutan di udara melalui turbulensinya lebih rendah sehingga polutan mudah terakumulasi.

Konsentrasi CO terukur untuk setiap titik pengukuran masih berada di bawah baku mutu. Hal ini berdasarkan PP No. 41 Tahun 1999, tentang pengendalian pencemaran udara, baku mutu udara ambien untuk $\mathrm{CO}$ adalah $30.000 \mu \mathrm{g} / \mathrm{Nm}^{3}$, setara dengan 30 ppm.

\section{Analisis Regresi dan Korelasi}

Analisis korelasi yang digunakan adalah regresi linear sederhana. Variabel yang diukur adalah konsentrasi CO dengan jumlah kendaraan. Hal ini bertujuan untuk mengetahui hubungan antara konsentrasi CO dengan jumlah kendaraan tersebut. Pada setiap lokasi pengukuran, hubungan variabel ditentukan berdasarkan data yang diambil setiap lima menit selama satu jam.

Korelasi konsentrasi CO terhadap kendaraan bermotor yang kuat dan sangat kuat juga diperlihatkan di kawasan pasar tradisional Kota Padang dengan nilai $\mathrm{r}$ sebesar 0,54$0,93 \quad\left(R^{2}=0,2883-0,8676\right)$. Hubungan konsentrasi $\mathrm{CO}$ dengan jumlah kendaraan untuk tiap pasar tradisional pada saat jam sibuk dan jam senggang dapat dilihat pada gambar 7 sampai dengan gambar 12 .

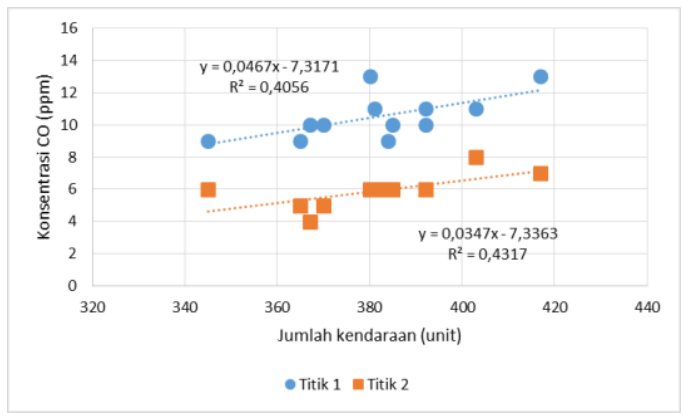

Gambar 7. Hubungan jumlah kendaraan dan konsentrasi CO pada jam sibuk di Pasar Bandar Buat

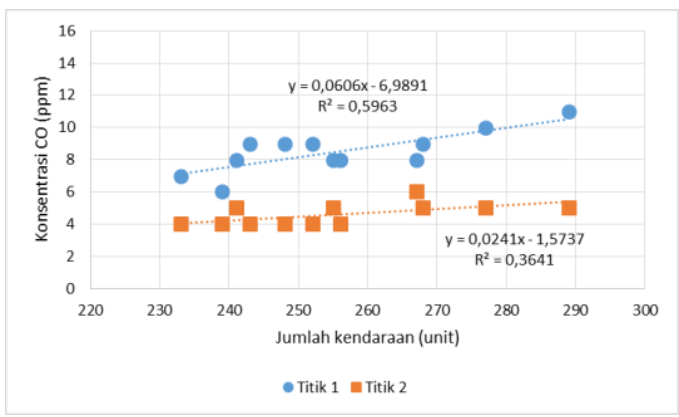

Gambar 8. Hubungan jumlah kendaraan dan konsentrasi CO pada jam senggang di Pasar

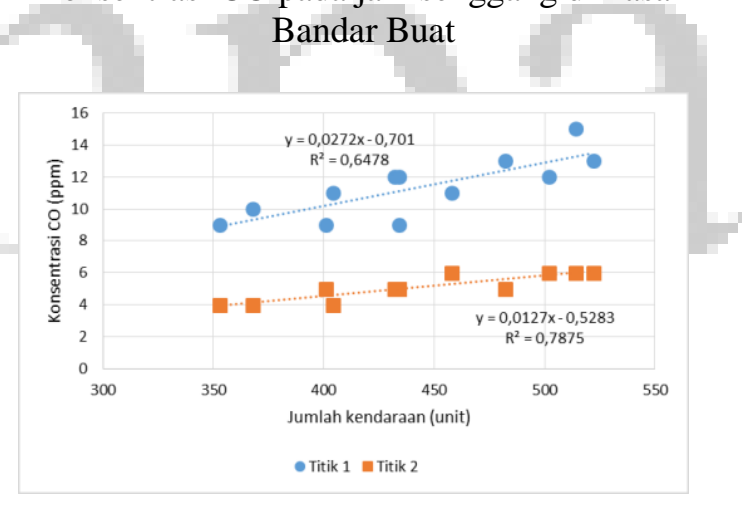

Gambar 9. Hubungan jumlah kendaraan dan konsentrasi CO pada jam sibuk di Pasar Lubuk Buaya 


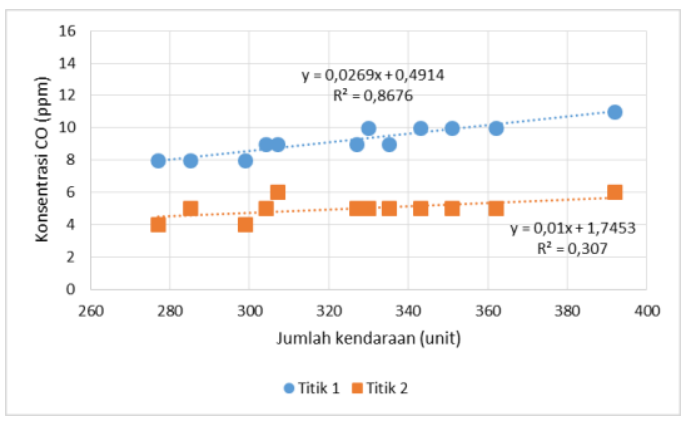

Gambar 10. Hubungan jumlah kendaraan dan konsentrasi CO pada jam senggang di Pasar Lubuk Buaya

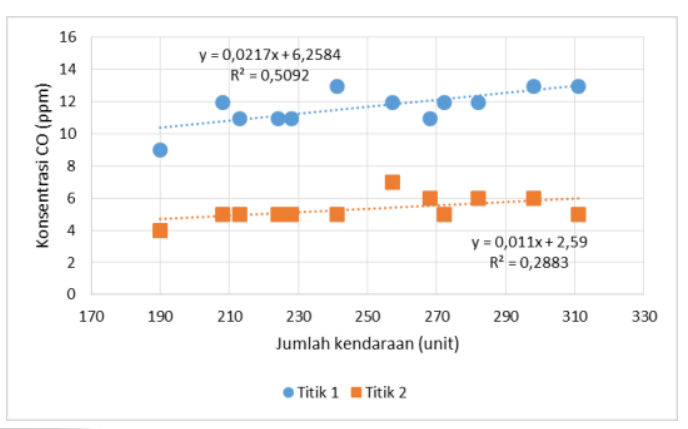

Gambar 11. Hubungan jumlah kendaraan dan konsentrasi CO pada jam sibuk di Pasar Raya

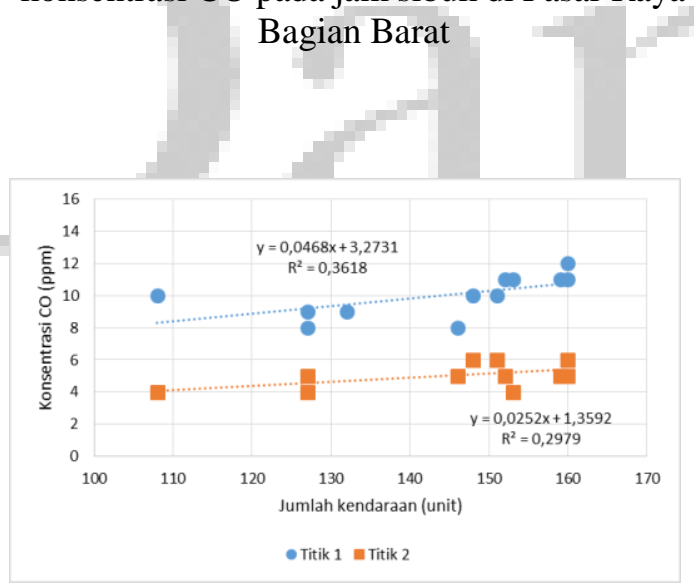

Gambar 12. Hubungan jumlah kendaraan dan konsentrasi CO pada jam senggang di Pasar Raya Bagian Barat

Untuk pengukuran di luar kawasan pasar tradisonal (titik 1), hubungan tertinggi antara konsentrasi $\mathrm{CO}$ dengan jumlah total kendaraan terdapat pada kawasan Pasar Lubuk Buaya saat jam senggang dengan korelasi $\quad 0,93 \quad\left(\mathrm{R}^{2}=0,8676\right)$, sedangkan hubungan terendah terdapat Pasar Raya bagian Barat saat jam senggang dengan nilai korelasi 0,60 $\left(\mathrm{R}^{2}=0,3618\right)$.
Pada pengukuran di dalam kawasan pasar tradisional (titik 2), hubungan tertinggi antara konsentrasi CO dengan jumlah total kendaraan terdapat pada kawasan Pasar Lubuk Buaya saat jam sibuk dengan nilai korelasi $0,89 \quad\left(\mathrm{R}^{2}=0,7875\right), \quad$ sedangkan hubungan terendah terdapat Pasar Raya bagian Barat saat jam sibuk dengan nilai korelasi $0,54\left(\mathrm{R}^{2}=0,2883\right)$.

\section{SIMPULAN}

Konsentrasi CO di kawasan pasar tradisional di Kota Padang saat jam kendaraan puncak sebesar 5,92 - 11,67 ppm, sedangkan pada jam senggang berada dalam rentang 4,58 9,25 ppm. Saat posisi titik pengukuran di tempat yang lebih dekat ke jalan raya konsentrasi $\mathrm{CO}$ terukur lebih tinggi.

Hasil pengukuran konsentrasi $\mathrm{CO}$ di setiap lokasi pasar tradisional masih berada di bawah baku mutu PP No. 41 Tahun 1999 tentang Pengendalian Pencemaran Udara.

Konsentrasi $\mathrm{CO}$ yang terukur berhubungan dengan jumlah kendaraan (unit) di lokasi studi dengan korelasi cukup kuat sampai sangat kuat $(0,54-0,93)$.

\section{DAFTAR PUSTAKA}

Abubakar, I. 2001. Kerusakan Lingkungan yang Diakibatkan oleh Sumber Transportasi. www.bplhdjabar.co.id diakses 18 Agustus 2012.

Bachtiar, V.S., Hidayat, T., Purnawan, Laksono, H.D. 2016. Urban Scale Mapping of $\mathrm{CO}$ Concentrations due to the Transport Sector in Padang City. Proceeding the $4^{\text {th }}$ International Conference on Sustainable Built and Environment, Sustainable Building and Enironmmen for Sophisticated Life, October 12-14, 2016, Yogyakarta, ISSN 2541-223X.

Bachtiar, V.S. 2005. Kajian Hubungan Antara Variasi Kecepatan Kendaraan dengan Emisi yang dikeluarkan pada Kendaraan Bermotor Roda Empat', Jurnal, p. 2.

Badan Pusat Statistika, 2012. Padang Dalam Angka 2011. 
Istantinova, D.B., Hadiwidodo, M., Handayani, D.S. 2012. Pengaruh Kecepatan Angin, Kelembaban Dan Suhu Udara Terhadap Konsentrasi Gas Pencemar Sulfur Dioksida (So2) Dalam Udara Ambien Di Sekitar Pt. Inti General Yaja Steel Semarang. http://download.portalgaruda.org/articl e.php? article $=73378 \&$ val $=4690$.

Peraturan Pemerintah No. 41 Tahun 1999, tentang Pengendalian Pencemaran Udara
Putut, E, 2011. Simulasi Model Dispersi Karbon Monoksida di Pintu Masuk Tol. Pasca Sarjana. Fak. Farmasi

Supriyadi, E. 2009. Penerapan Model Finite Length Line Source untuk Menduga Konsentrasi Polutan dari Sumber Garis (Studi Kasus: Jl. M.H. Thamrin, DKI Jakarta) Tugas Akhir Institut Pertanian Bogo

Suryani, A. S. 2010. Studi Beban Emisi Pencemaran Udara Karbon Monoksida dari Kendaraan Bermotor di DKI Jakarta.

Zulaela, 2010. Business Forecasting with Microsoft Excel. Program Magister Menejemen Univ. Padjajaran
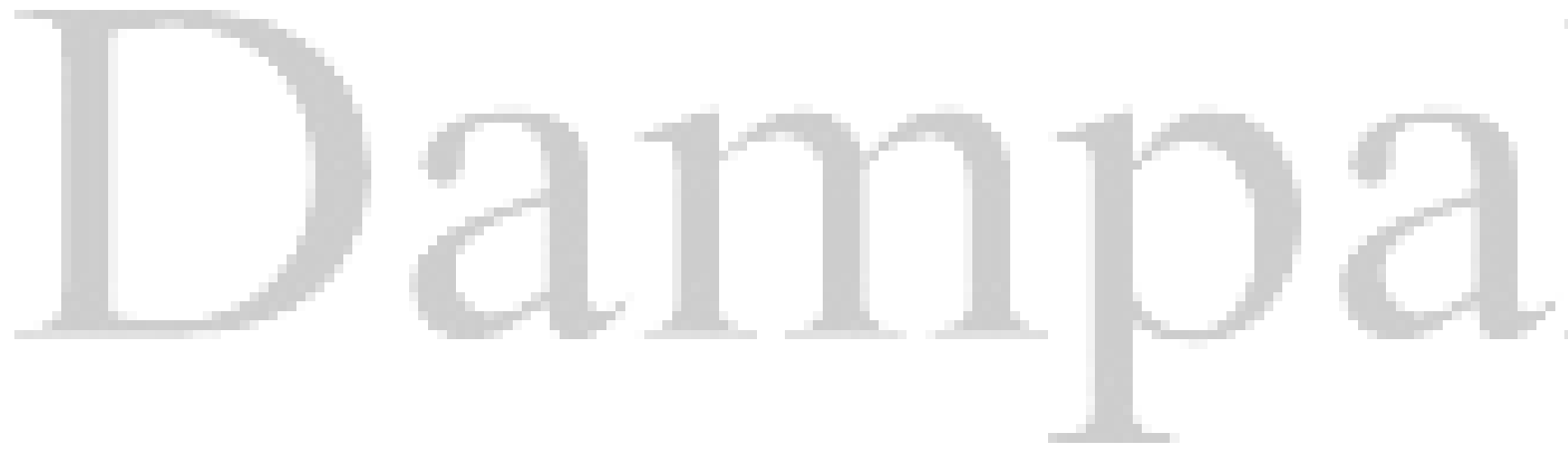